\title{
Defining and predicting the 'break of the season' for north-east Queensland grazing areas
}

\author{
Jacqueline Balston ${ }^{\mathrm{A}, \mathrm{C}}$ and Bernie English ${ }^{\mathrm{B}}$ \\ ${ }^{\text {A }}$ Queensland Climate Change Centre of Excellence, PO Box 937, Cairns, QLD 4870, Australia. \\ ${ }^{B}$ Queensland Department of Primary Industries and Fisheries (QDPI\&F), Kairi, QLD 4872, Australia. \\ ${ }^{\mathrm{C}}$ Corresponding author. Email: jacqueline.balston@jbalston.com
}

\begin{abstract}
For pasture growth in the semi-arid tropics of north-east Australia, where up to $80 \%$ of annual rainfall occurs between December and March, the timing and distribution of rainfall events is often more important than the total amount. In particular, the timing of the 'green break of the season' (GBOS) at the end of the dry season, when new pasture growth becomes available as forage and a live-weight gain is measured in cattle, affects several important management decisions that prevent overgrazing and pasture degradation. Currently, beef producers in the region use a GBOS rule based on rainfall (e.g. $40 \mathrm{~mm}$ of rain over three days by 1 December) to define the event and make their management decisions. A survey of 16 beef producers in north-east Queensland shows three quarters of respondents use a rainfall amount that occurs in only half or less than half of all years at their location. In addition, only half the producers expect the GBOS to occur within two weeks of the median date calculated by the CSIRO plant growth days model GRIM. This result suggests that in the producer rules, either the rainfall quantity or the period of time over which the rain is expected, is unrealistic. Despite only $37 \%$ of beef producers indicating that they use a southern oscillation index (SOI) forecast in their decisions, cross validated LEPS (linear error in probability space) analyses showed both the average 3 month July-September SOI and the 2 month August-September SOI have significant forecast skill in predicting the probability of both the amount of wet season rainfall and the timing of the GBOS. The communication and implementation of a rigorous and realistic definition of the GBOS, and the likely impacts of anthropogenic climate change on the region are discussed in the context of the sustainable management of northern Australian rangelands.
\end{abstract}

Additional keywords: climate, forecasting, management, sustainable.

\section{Introduction}

The climate, and in particular the rainfall, of the semi-arid tropics of north-east Australia is one of the most variable on earth-the result of interactions from several climate systems including the Madden Julian oscillation, the Australian monsoon, the El Niño southern oscillation (ENSO), which alone is responsible for up to $40 \%$ of the rainfall variability in eastern Australia, and decadal to multidecadal cycles (Cordery 1998; Allan 2000). Up to $80 \%$ of the rainfall occurs between October and March - the summer 'wet season', much of which may either run off or infiltrate to a deep level below the root bed, depending on the timing and distribution of rainfall events and ground cover. The resultant variability in pasture growth makes it difficult for managers to match animal numbers to forage supply and creates the most significant risk in the management of tropical grazing lands (McCown 1981b; O'Rourke et al. 1991). Beef producers in the region have traditionally grazed their pastures using relatively constant numbers set to the average season, although rotational grazing practices such as wet season spelling and time controlled grazing are becoming increasingly common. However, continuous stocking can still lead to wide-spread overgrazing and degradation of pastures, poor animal performance and increased cattle deaths in dry years (McKeon et al. 2004).

From a grazing perspective, a forecast of when the wet season will start, and in particular a forecast of when there will be sufficient new season grass for liveweight gain in stock [the 'green break of the season' (GBOS)], would be invaluable for making several management decisions. Prior to the GBOS pastures have dried off and in some years the surface water supplies are low. At this time of the year, producers need to know how much supplementary stock feed will be required, when they may need to change stock supplements from a dry season lick of urea to a wet season lick of phosphorus, how many cattle they may be able to run on a particular block until the GBOS occurs, what pasture rotations to implement, whether to burn pastures for woody weed control, or if stock should be sold, bought or moved. Each of these decisions requires information on how much forage is left (pasture condition) and when the GBOS will occur to produce new green pasture and a liveweight gain in their cattle.

Currently most beef producers in the dry tropics region of north-east Queensland have a simple GBOS rule based on rainfall amounts (e.g. $40 \mathrm{~mm}$ over a 3-day period by 1 December) that 
defines how much rain they believe is required for a GBOS and when they think the event will occur (Hargreaves 1975; Huda et al. 1991; O'Rourke et al. 1991; Park et al. 2001). These simple rules can be easily calculated from historical rainfall records. However, it is not known whether these simple GBOS rules are accurate for estimates of either the amount of rainfall required to achieve a GBOS, or for forecasting the timing of the event. More complex definitions of the GBOS involve thresholds of stored soil water (e.g. Slatyer 1964) but these too will not always identify the initiation of green forage as the pasture response can occur as a result of small, sequential amounts of rainfall that do not exceed the defined stored soil water threshold (McCown 1981b). Other authors (e.g. McCown 1981b, 1982; McCown et al. 1981; O'Rourke et al. 1991) have defined the start of the GBOS as the week in which a period of sustained liveweight gain in cattle was initiated. McCown (1981a), for example, defined the GBOS as the first four weeks, and six of a total of eight consecutive weeks, when a calculated growth index (the product of a moisture index from a basic water-balance model and temperature) corresponded with sufficient pasture growth for liveweight gain in cattle. However, this method is somewhat complex and does not translate into a simple rainfall rule that is familiar to beef producers.

Even more complex are computer models of pasture growth such as GRIM - plant growth daily (McDonald 1994), and GRASP - plant growth and biomass (McKeon et al. 2000), which calculate the number of 'green days', or days when there is green forage growth, for a variety of pastures. For these models, there is a high correlation between the number of calculated green days in a year and annual liveweight gain in stock. However, the models require considerable parameterisation and the generation of outputs requires technical and computational expertise not accessible to most producers in a timely or spatially specific format. This paper examines the current simple rainfall GBOS rules used by beef producers in north-east Queensland to determine how realistic they are for identifying a GBOS, and how their rules compare with a rule generated by the plant growth model GRIM. Additionally, the skill in using the southern oscillation index (SOI), a measure of the state of the El Niño southern oscillation, to predict both total wet season rainfall and the timing of the GBOS is examined. Finally, the likely changes to rainfall and available moisture in the region as a result of anthropogenic climate change, and the validity of using SOI based forecasting systems in the future, are reviewed and discussed.

\section{Materials and methods}

Study area

The study area extended through the dry tropical grazing country of north-east Queensland from Mount Garnet in the north to Ravenswood in the south (Fig. 1). Median annual rainfall ranges from $767 \mathrm{~mm}$ at Mount Garnet to $578 \mathrm{~mm}$ at Hillgrove, and median wet season rainfall ranges from $587 \mathrm{~mm}$ at Mount Garnet to $357 \mathrm{~mm}$ at Hillgrove (Clewett et al. 1994).

Soils in the area range from fertile clays and other fertile soils derived from basalts, to lower fertility soils derived from granites and metamorphics. Most of the region has a ground cover of tall monsoon grass or mid-grass species such as black spear grass (Heteropogon contortus (L.) Beauv.), kangaroo grass (Themeda

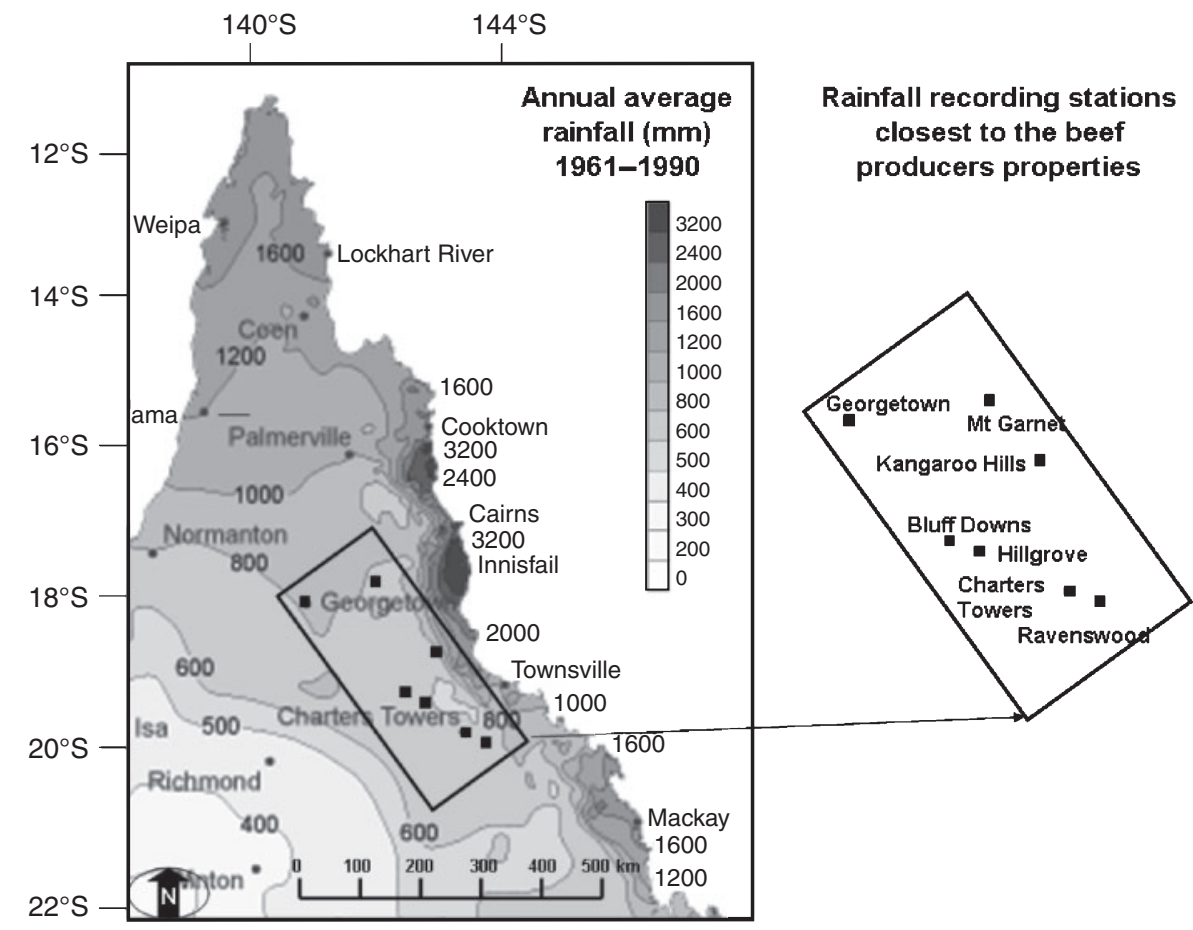

Fig. 1. Map of north-east Queensland, Australia showing average annual rainfall (1961-90) and the study area (Adapted from Bureau of Meteorology 2008). The inset shows rainfall recording stations identified by beef producers in the study area as their closest station. 
triandra Forssk.), blue grasses (Bothriochloa spp. and Dichanthium spp.), sorghums (Sarga spp.) and wire grasses (Aristida spp.). Other native and introduced species include firegrass (Schizachyrium spp.), Mitchell grass (Astrebla spp.) and Indian couch (Bothriochloa pertusa (L.) A. Camus) (Tothill and Gillies 1992; Ash et al. 2001).

\section{Producer survey}

A survey of beef producers across the study area was undertaken to record their current definitions for the GBOS and the timing of the event from their experience. Questionnaires were handed out by Queensland Department of Primary Industries and Fisheries beef extension staff at the end of industry meetings in the area. Producers were asked to identify their closest rainfall station, major soil type and dominant pasture species. They were then asked 'how much rain do you consider is needed to break the dry season and produce useful pasture growth (i.e. a GBOS)?' and 'from your experience/station records what do you think is the 'average' date for the GBOS for your area?' Additional information including their use of climate forecasting tools was also recorded. Results were returned by sixteen beef producers and collated. The probability that each producer's GBOS rule had occurred by the date identified was tested using historical rainfall data for the producer's closest rainfall station using Australian Rainman StreamFlow (Version 4.3) (Clewett et al. 2003). Results were plotted for all the years in the record, for the years when the August-September SOI phase was consistently positive (indicative of a La Niña event), and for the years when the August-September SOI phase was consistently negative (indicative of an El Niño event).

\section{Plant growth model}

To determine how realistic the producer's GBOS rule were, the CSIRO developed growth index model (GRIM) was used. GRIM calculates the impact of climate on tropical pasture grass growth (McDonald 1994). Model outputs have been validated against liveweight gain in cattle in previous studies at Ravenswood in the study region (A. Ash, personal communication). For this reason, Ravenswood rainfall and climate data (1890-2005) was used to calculate the timing of the GBOS using GRIM. Inputs to the model included daily rainfall data for Ravenswood, monthly averages of evaporation, dry and wet bulb temperature (for the calculation of vapour pressure deficit), maximum and minimum air temperature, wind and radiation. A typical soil profile for the Ravenswood area was parameterised and included field capacity and wilting point. Evapotranspiration and growth indices for $\mathrm{C}_{3}$ megatherm pasture species (representative of the typically mixed pasture community in the area) were entered.

A 'green day' as defined by the program was a day when soil moisture exceeded $10 \%$ of field capacity and the date that the GBOS occurs was defined as the date by which a minimum of 21 green days in any 4-week period occurred to replicate conditions in which liveweight gain had been recorded in cattle. Output from the model was the number of green days in each week. Assumptions were that starting soil moisture at the beginning of the record in 1890 was zero and there was no runoff. As most pasture species in the area don't start to grow until minimum temperatures rise above $\sim 14^{\circ} \mathrm{C}$, GBOS events before
1 October were not included so as to ensure that false breaks (when the temperature would not have been high enough to sustain pasture growth) were not included. The median date of the GBOS event for all the years as calculated by GRIM was used to generate a simple rainfall rule to compare with those used by producers.

\section{Forecast analysis}

The state of ENSO is measured in several ways including sea surface temperatures, equatorial winds, trade wind anomalies and the SOI. The SOI referred to in this study is based on algorithms developed by Troup (1965). High positive values of the SOI represent a La Niña, an event associated with higher probabilities of above average rainfall across northern and eastern Australia, a stronger, more southerly displaced monsoon trough and increase in tropical cyclone numbers in the Coral Sea. High negative values of the SOI are indicative of an El Niño and associated reduction in rainfall probabilities across northern and eastern Australia, a weaker, more northerly displaced monsoon trough and a reduction in the number of tropical cyclones affecting the east coast.

The non-parametric standardised cross validated KruskalWallis (KW) (Stone and Auliciems 1992), Kolmogorov-Smirnov (KS) (Conover 1971) and linear error in probability space (LEPS) (Potts et al. 1996) analyses are considered the standard statistical analyses for evaluating the skill of seasonal rainfall forecasts. Non-parametric tests are used as rainfall data is usually skewed and so not suitable for use in a standard $F$-test. For this study the KW, KS and LEPS analyses in Australian Rainman StreamFlow (Version 4.3) (Clewett et al. 2003) were used to determine the skill of both the 2 month August-September SOI phase (positive, rising, neutral, falling and negative) and the 3 month average July-September SOI (SOI below -5 , between -5 and +5 and SOI above +5 ) to forecast both total wet season rainfall and the timing of the GBOS as defined by the simple rainfall rule developed from the GRIM analysis.

\section{Results}

\section{Producer survey}

The simple rainfall based GBOS rules used by producers varied considerably, and are probably a reflection of differences in historical knowledge and personal experience. Results of the analysis that compared producer's GBOS rules with historical records of rainfall show that 12 out of the 16 producers use a rule that occurred in less than half of all years at their location, and two of the producers have a rainfall rule that has never occurred in any of the 115 years on record (Fig. 2). Only six of the survey respondents indicated that they use a SOI based seasonal forecast in their management, and two others used another unspecified seasonal forecast. For each producer GBOS rule, the probability of the event occurring was highest when the August-September SOI was positive compared with the all years or AugustSeptember SOI negative years.

\section{Plant growth model}

The median date for the GBOS at Ravenswood as calculated from the outputs of the GRIM plant growth model was 16 December. The earliest break occurred on 30 October (1924), and there was 


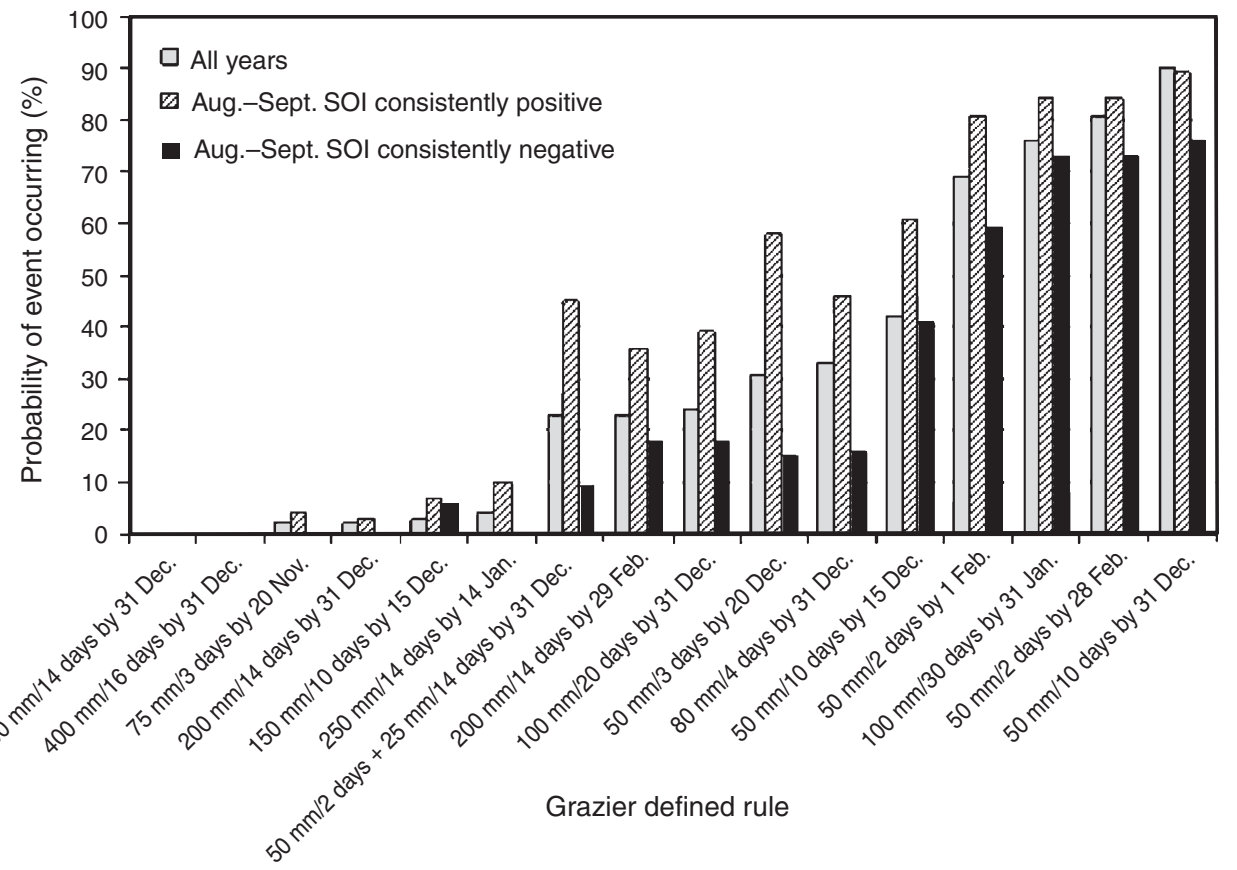

Fig. 2. Green break of season (GBOS) rainfall rules nominated by beef producer s in a survey and their likelihood of occurrence. The probability that each rule occurs was calculated using the program Australian Rainman StreamFlow (Version 4.3). Probabilities are shown for: all 105 years in the record, El Niño years (as defined by a consistently negative August-September SOI) and La Niña years (as defined by a consistently positive August-September SOI).

one year in the record during the federation drought (1901) when a green break did not occur (Fig. 3). The median date of the GBOS for the years 1970-94 (the years that producers in the region would remember best but was a period dominated by La Niña events) was 3 December, nearly 2 weeks earlier than the all years date. Several simple rainfall GBOS rules were tested using Australian Rainman StreamFlow for various amounts of rainfall (5-100 mm) over various numbers of days (5-30 days). Using all the years on record, the rule which best replicated the probability curve of dates generated by GRIM and that had a median date of 16 December was $57 \mathrm{~mm}$ over 21 days.

\section{Forecast analysis}

Using Ravenswood data, the KW and LEPS analysis of the two SOI predictors [the 2 month (August-September) SOI phase and the 3 month average (July-September) SOI], showed both predictors have significant skill $(\mathrm{KW}>0.99$; LEPS > 7.6;

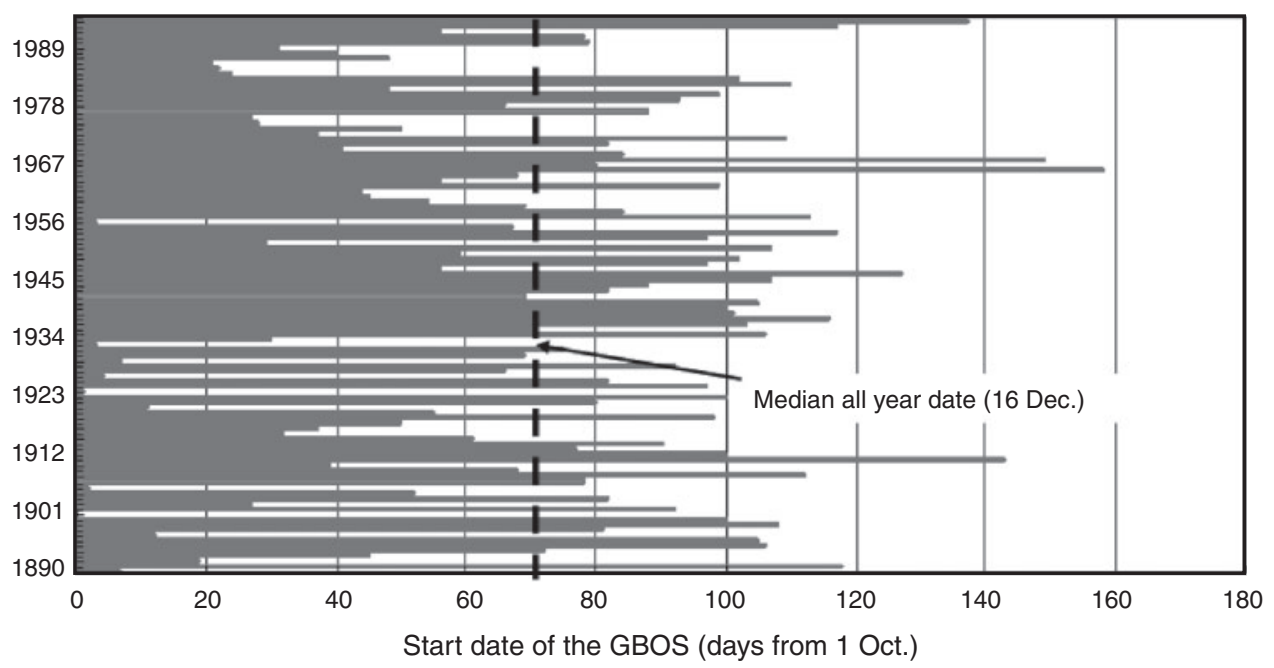

Fig. 3. Number of days from 1 October each year to the green break of season (GBOS) as calculated by the CSIRO pasture model GRIM for Ravenswood (1890-1996). False breaks before 1 October are not included. 
$P>0.99)$ in forecasting wet season rainfall at Ravenswood for the years tested (1890-2005) (Fig. 4). In the case of the SOI phases, there was a significant increase in the probability of receiving rainfall when the August-September SOI phase was positive $(\mathrm{KS}=0.999)$, and a significant decrease in the probability if the August-September SOI was negative $(\mathrm{KS}=0.995)$ compared with the all years distribution. The three other SOI phases (falling, neutral and raising) were not significantly different from the all-year distribution. For the average 3 month SOI predictor, a SOI above +5 and a SOI below -5 were each significantly different $(\mathrm{KS}=0.999)$ from the all-year distribution. This result indicates that ENSO is a significant driver of rainfall variability in the region at this time of year and that

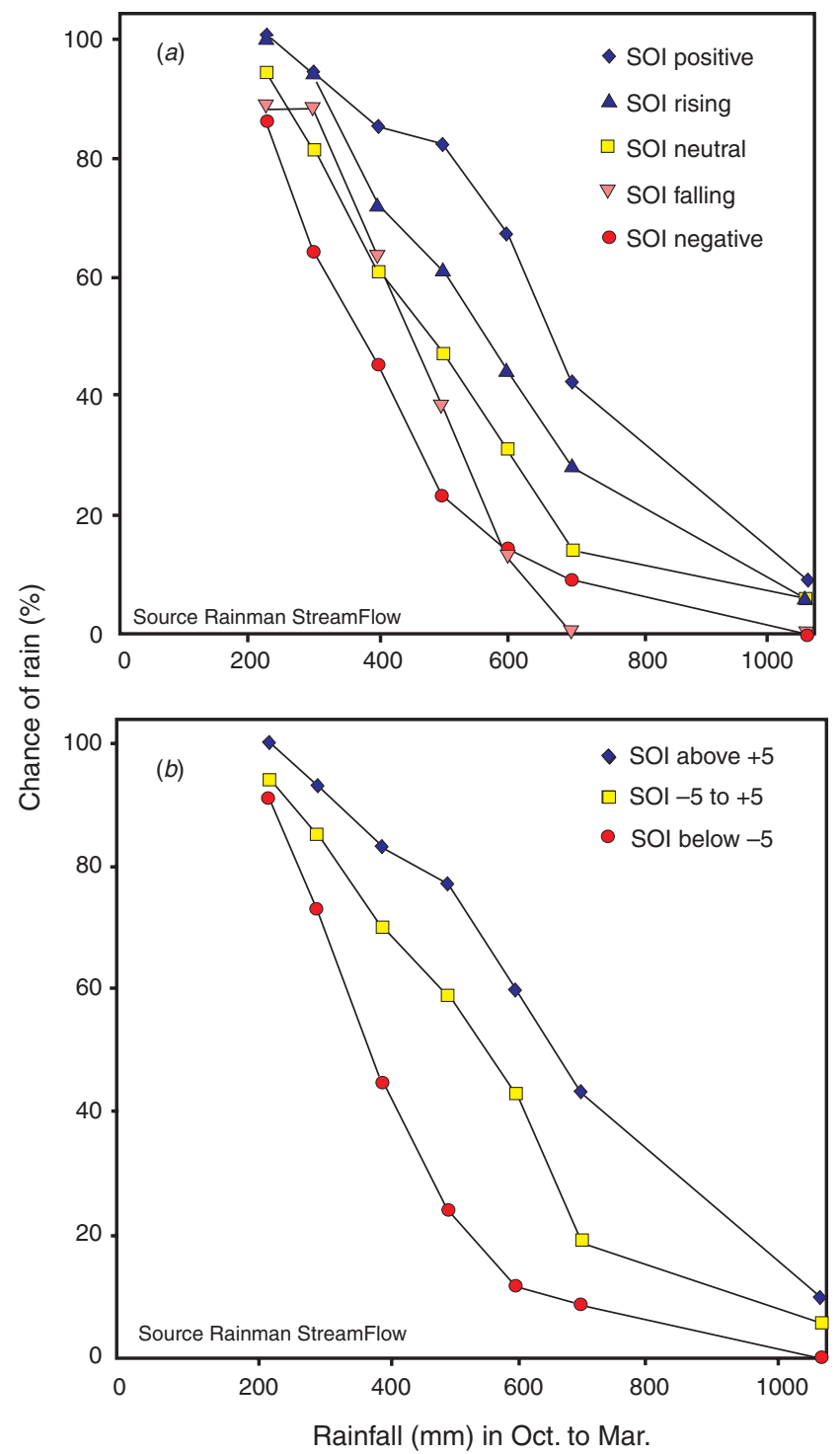

Fig. 4. The relationship between the SOI and total wet season (October-March) rainfall at Ravenswood (1890-2005) as defined by $(a)$ the 2 month August-September SOI phase and $(b)$ the July-September 3 month average SOI. The cross validated LEPS score $(>7.6 ; P=0.99)$ and $\mathrm{KS}$ test $(\mathrm{KS}>0.99)$ were significant in both cases (Australian Rainman StreamFlow Version 4.3). the SOI has potential as a forecasting tool for grazing decisions related to total wet season rainfall.

The KW and LEPS analysis was again used of to determine the skill of the two SOI predictors to forecast the timing of the GBOS (using the $57 \mathrm{~mm}$ of rainfall over 21 days between 1 October and 31 March rule) at Ravenswood. Results showed again that each predictor has significant skill $(\mathrm{KW}=0.991$; LEPS $>7.6 ; P>0.95)$ (Fig. 5). For the average 3 month SOI predictor, a SOI below -5 and a SOI above +5 were each significantly different $(\mathrm{KS}=0.993$ and $\mathrm{KS}=0.998$, respectively) from the all-year distribution. For the phases, again just the SOI positive $(\mathrm{KS}=0.997)$ and SOI negative phases $(\mathrm{KS}=0.98)$ were significantly different to the allyear distribution. Graphs indicate that the median date of the first GBOS event shifts from late November to mid January depending on the state of ENSO at the end of September.

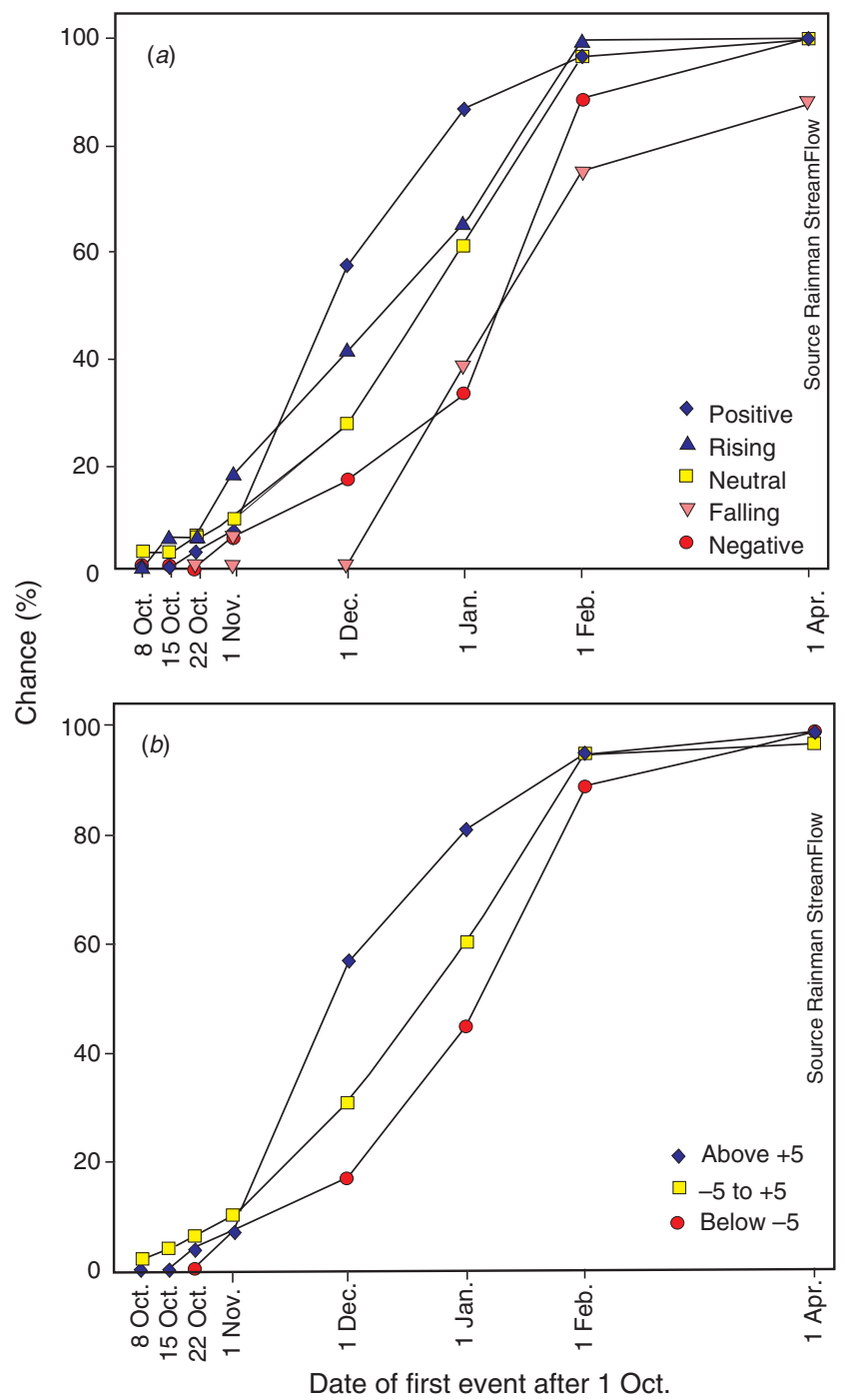

Fig. 5. The probability of a GBOS $57 \mathrm{~mm}$ rainfall event over 21 days between 1 October and 31 March at Ravenswood (1887-2005) using (a) the August-September 2 month SOI phase and $(b)$ the July-September average 3 month SOI. Skill score is measured by a cross validated LEPS analysis. The cross validated LEPS score $(>7.6 ; P=0.99)$ and $\mathrm{KS}$ test $(\mathrm{KS}>0.95)$ were significant in both cases (Australian Rainman StreamFlow Version 4.3). 
A comparison of the median date of the GBOS as defined by producers, and the probability of the GBOS occurring as defined by GRIM, was plotted (Fig. 6). Four of the 16 beef producers defined a median GBOS date that was earlier or on the median date for all the years in the record as calculated by GRIM. Twelve producers nominated a date that was later. Only half of the producers expected the GBOS to occur within 2 weeks of the median date calculated by GRIM.

A spatial analysis of all 26 rainfall stations in the study region was undertaken using the mapping capacity in Australian Rainman StreamFlow to determine the transferability of these results to other locations in the area. The average SOI was a significant predictor of wet season (October-March) rainfall at $96 \%$ of stations and the SOI phases forecast was significant at $85 \%$ of stations (LEPS skill score $>7.6 ; P=0.90$ ). A spatial test of the skill of each predictor to determine the timing of the GBOS as defined by GRIM showed the average SOI was significant at $85 \%$ of stations and the SOI phases at $74 \%$ of stations (LEPS skill score $>7.6 ; P=0.90$ ). These results indicate that conclusions drawn from the Ravenswood analysis are, in general, representative of the study area.

\section{Discussion}

\section{Producer expectations}

Earlier studies have identified break of season rules (e.g. Hargreaves 1975; Huda et al. 1991; O'Rourke et al. 1991; Park et al. 2001), but none have determined how realistic beef producer's rules are at defining the GBOS. Results from the producer survey in this study indicate that in more than half of years on record three quarters of the beef producer's GBOS rule did not occur by the date they indicated. Similarly, only half of the producers had an expectation that the timing of the GBOS would occur within 2 weeks of that calculated by the GRIM rule. Four of the 16 beef producer's rules identified a GBOS earlier than the median date as calculated by GRIM and the remainder predicted a later date - some over a month later. It appears then, that most of the producer definitions of the timing of the GBOS are inaccurate - either with respect to the amount of rain received or the length of time over which the rain falls. Those beef producers who have unrealistic expectations of when the GBOS occurs will likely make decisions that lead to unsustainable overgrazing at the end of the season, particularly when exacerbated by El Niño years or drought events (McKeon and White 1992; McKeon et al. 2004). Further, drought events have been identified as one of the contributing factors to past pasture degradation events across northern Australia (McKeon et al. 2004).

The small survey size of this study gives only some indication of the rules that beef producers in the area use, and others may have a more realistic understandings of the amount of rainfall they receive and when. Regardless, the usefulness of ENSO across the region is significant. In this study the GBOS is shifted forward by up to 6 weeks depending on the state of ENSO, a result that indicates that the use of an SOI forecast would be a valuable tool in making GBOS decisions in this region. The finding that only half of the producers questioned use a SOI climate forecast would suggest that, although aware of climate issues, the practical application of the information is not well understood. In a similar study of pastoralists in the Gascoyne-Murchison region of Western Australia, where more than half of the respondents

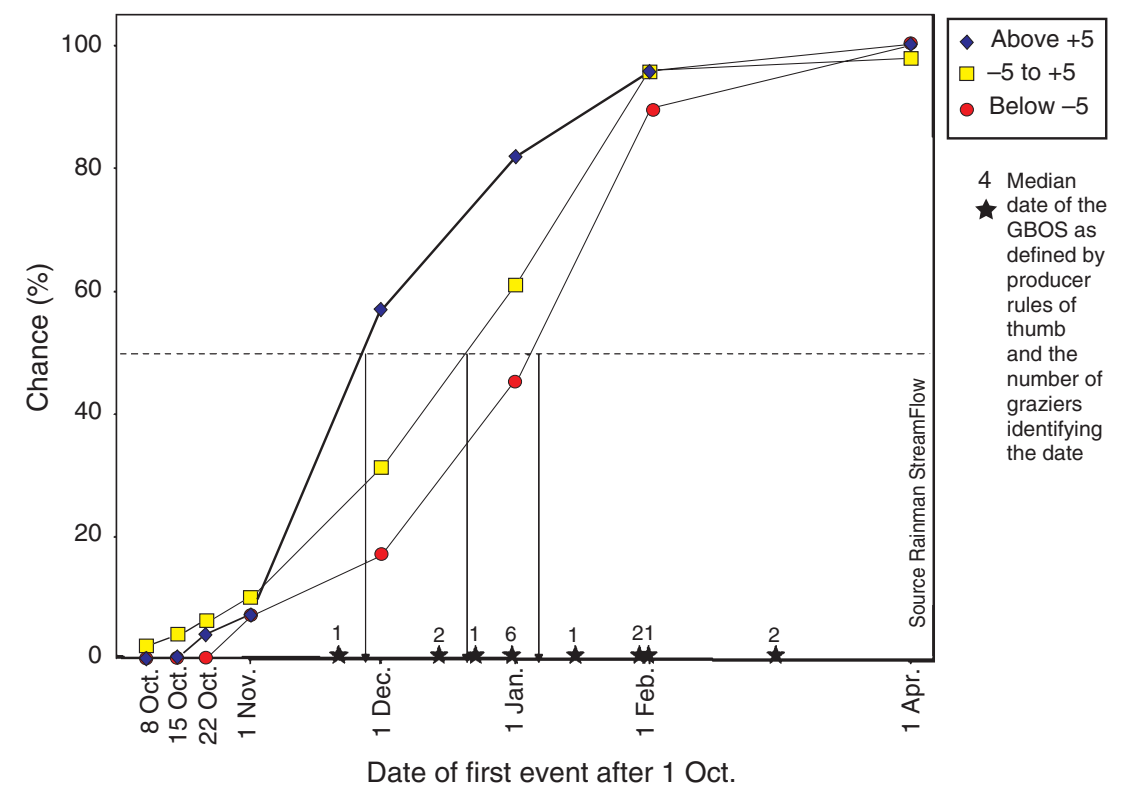

Fig. 6. The probability of a GBOS event $(57 \mathrm{~mm}$ rainfall over 21 days between 1 October and 31 March) at Ravenswood (1887-2005) using the July-September average 3 month SOI. The vertical lines indicate the median date of the GBOS rainfall event in (from left to right) La Niña years (SOI above +5: 22 November), all years (SOI between -5 and +5: 16 December) and El Niño years (SOI less than $-5: 2$ January). Stars indicate the median date of the GBOS as expected by surveyed beef producers. 
indicated that they used climate and weather information regularly, $80 \%$ had poor technical understanding on how to interpret the standard wording of a probabilistic forecast (Keogh et al. 2005). These results highlight the need for the communication of both realistic and practical information possibly translated into simple rainfall rules that can be used by producers to manage for the GBOS.

\section{Long-term cycles}

In addition to intra-annual seasonal variability and that driven by ENSO, there are several longer cycles in the climate that impact on the region including biennial, decadal and inter-decadal cycles (Allan 2000). However, it is likely that many of the beef producer's estimates of when the GBOS will occur are based on their experience of the climate since living in the region. When calculated by GRIM using data for the past 30 years, the average date of the GBOS at Ravenswood occurs on 3 December. However, if the full record of rainfall data over the past 105 years is used, the median date of the GBOS is nearly 2 weeks later (16 December). This result highlights the fact that results in data analysis and expectation based on personal experience can be quite different depending on the time-series of data available. In this case, the 1970s were an unusually wet decade, a perturbation that has skewed both the historical analysis and perhaps some producer expectations towards an earlier, and in the long term, unrealistic timing for the GBOS.

\section{Forecast analysis}

Results from this and earlier studies (e.g. Allan 1988; Evans and Allan 1992) show a significant influence from ENSO on rainfall across the region. In this study, there was a significant shift in the probability of above or below median wet season rainfall at Ravenswood depending on the July-September SOI. The cross validated LEPS analysis identified the preceding 2 month SOI phase and the 3 month average SOI as significant predictors of total wet season (October-March) rainfall. This result suggests that use of an SOI predictor, in conjunction with a measure of land condition, can provide valuable information at a time of the year when beef producers make decisions about the management of land at the end of the dry season. It should be noted, however, that the relationship between the SOI and rainfall across the region has varied over time (e.g. Power et al. 1988), and so the SOI may not always be a significant predictor of rainfall for the area. Although rainfall patterns across the region are relatively homogenous, ideally, a rainfall rule would be developed for each region to ensure expectations are as realistic as possible.

A future option for validating break of season rules may be to employ remote sensing and satellite technologies, as has been done in some areas to estimate plant performance in crop yields (Badhwar 1980; Reynolds et al. 2000) and herbage response in arid grazing areas (Bastin et al. 1996). Improvements in the moderate resolution imaging spectroradiometer (MODIS) technology onboard NASA' a Terra spacecraft, and a reduction in signal noise from atmospheric and cloud conditions has allowed MODIS to monitor vegetation phenology including 'greenup' (date of onset of photosynthetic activity) with good success (Zhang et al. 2003). These data could then be used to determine the GBOS on larger spatial scales when undertaken in conjunction with on-ground observations for the calibration of remote sensed measurements.

\section{Climate change}

The future climate of the region will likely differ from that of today as a result of the influences from anthropogenic greenhouse gas emissions. Several studies that have examined the impact of climate change on ENSO indicate that there may be an increase in the frequency of El Niño events in response to rises in global temperature (Herbert and Dixon 2002; Huber and Caballero 2003; Tsonis et al.2005) or the climate may tend to a 'near El Niño mean state'(IPCC 2001). Global climate models predict that both spring and summer rainfall across the study area will continue to decrease by up to 5\% per degree of warming (Walsh et al. 2001). In addition, there will likely be changes to cyclone activity and the strength and timing of the monsoon (IPCC 2007).

Other changes to rainfall in the region as a result of climate change include an expected increase in the frequency of extreme rainfall events. As an example, the likely return period for an $80 \mathrm{~mm}$ per day extreme rainfall event in north Queensland is expected to drop from 40 to 20 years (Walsh et al. 2001). If rainfall events are more intense, the likelihood of runoff is increased and a drop in soil and available plant moisture results. In addition, most studies suggest that increased temperatures and evaporation/evapotranspiration would lead to hotter and drier droughts even if rainfall totals remain largely unaffected (Rosenzweig and Hillel 1998; Nicholls 2003; Risbey et al. 2003). To date, the rainfall data used in this study do not show any significant trend over time. However, other factors such as increased carbon dioxide levels and temperature will affect plant physiology and hence pasture response in currently unquantified ways.

Unrealistic expectations of the timing and strength of the GBOS are of even more concern when the effects of climate change are taken into account. With the risk that future expectations of the timing of the GBOS will be based on the current climate, it is essential that the likely impacts of climate change be communicated to managers of the northern grasslands. The calculation of realistic of rainfall rules based on grass models as have been developed in this study may be one tool that can be used to demonstrate a more realistic expectation. Additionally, the communication to beef producers of practical rainfall rules that include the impact of ENSO is considered useful.

In conclusion, beef producers in the dry tropics of north-east Queensland require a realistic expectation of when the green break of the season(GBOS) will occur to make sound decisions regarding pasture management towards the end of the dry season. A survey of beef producers in north-east Queensland indicated that $75 \%$ of beef producers use a rainfall rule to define the GBOS that in half of years on record did not occur by the date they indicated. In addition, only half of the producers expected the GBOS to occur within two weeks of the GBOS as calculated by the pasture model GRIM. These results suggest that producer expectations of the amount of rain required to generate a GBOS, or the period over which they expect the rain to fall, is unrealistic. The average 3 month (July-September) SOI and the 2 month (August-September) SOI phase both proved to be significant predictors of above or below median wet season (October-March) rainfall. In addition, each SOI 
predictor showed significant forecast skill in predicting the timing of the GBOS as defined by a simple rainfall rule based on outputs from the pasture model GRIM. Results highlight the need for the communication of a realistic definition of the GBOS and opportunity for the use of the SOI as a forecasting tool for the event.

\section{Acknowledgements}

The assistance of Campbell MacDonald (CSIRO), Andrew Ash (CSIRO), Neil White (QDNRW), David McClymont (QDNRW) and Sarah Lennox (QDNRW) is much appreciated.

\section{References}

Allan, R. J. (1988). El Niño southern oscillation influences in the Australasian region. Progress in Physical Geography 12, 313-348. doi: 10.1177/ 030913338801200301

Allan, R. J. (2000). ENSO and climatic variability in the last 150 years. In: 'El Niño and the Southern Oscillation: Multiscale Variability, Global and Regional Impacts'. (Eds H. F. Diaz and V. Markgraf.) pp. 3-55. (Cambridge University Press: Cambridge.)

Ash, A., Corfield, J., and Ksiksi, T. (2001). 'The Ecograze Project: Developing Guidelines to Better Manage Grazing Country.' (CSIRO: Townsville, NT.)

Badhwar, G. D. (1980). Crop emergence data determination from spectral data. Photogrammetric Engineering and Remote Sensing 46, 369-377.

Bastin, G. N., Pickup, G., and Stanes, A. (1996). Estimating landscape resilience from satellite data and its application to pastoral land management. The Rangeland Journal 18, 118-135. doi: 10.1071/ RJ9960118

Bureau of Meteorology (2008). Average annual and monthly rainfall. Available at: www.bom.gov.au/jsp/ncc/climate_averages/rainfall/index. jsp?period $=$ an $\&$ area $=q d$ (Accessed December 2008).

Clewett, J. F., Clarkson, N. N., Owens, D. T., and Abrecht, D. G. (1994), 'Australian Rainman: Rainfall Information for Better Management.' (Queensland Department of Primary Industries: Brisbane.)

Clewett, J. F., Clarkson, N. N., George, D. A., Ooi, S. H., Owens, D. T., Partridge, I. J., and Simpson, G. B. (2003). 'Rainman StreamFlow Version 4.3: a Comprehensive Climate and Streamflow Analysis Package on CD to Assess Seasonal Forecasts and Manage Climate Risk.' (Queensland Department of Primary Industries: Brisbane.)

Conover, W. J. (1971). 'Practical Non-Parametric Statistics.' (John Wiley \& Sons: New York.)

Cordery, I. (1998). Forecasting precipitation from atmospheric circulation and SOI. In: 'Hydrology in a Changing Environment'. (Eds H. Wheater and C. Kirby.) pp. 63-69. (British Hydrological Society: Exeter, UK.)

Evans, J. C., and Allan, R. J. (1992). El Niño/Southern oscillation modification to the structure of the monsoon and tropical cyclone activity in the Australasian region. International Journal of Climatology 12, 611-623. doi: 10.1002/joc.3370120607

Hargreaves, G. H. (1975). 'Water Requirements Manual for Irrigated Crops and Rainfed Agriculture.' (Utah State University Publications: Logan, UT.)

Herbert, J. M., and Dixon, R. W. (2002). Is the ENSO phenomenon changing as a result of global warming? Physical Geography 23, 196-211. doi: $10.2747 / 0272-3646.23 .3 .196$

Huber, M., and Caballero, R. (2003). Eocene El Niño: evidence for robust tropical dynamics in the "Hothouse". Science 299, 877-881. doi: 10.1126/ science. 1078766

Huda, A. K. S., Cogle, A. L., and Miller, C. P. (1991). 'Agroclimatic Analysis of Selected Locations in North Queensland.' (Queensland Department of Primary Industries: Brisbane.)
IPCC (2001). 'Climate Change: the Scientific Basis.' (Intergovernmental Panel on Climate Change: Geneva, Switzerland.)

IPCC (2007). 'Climatic Change: the Physical Science Basis.' (Intergovernmental Panel on Climate Change: Geneva, Switzerland.)

Keogh, D. U., Watson, I. W., Bell, K. L., Cobon, D. H., and Dutta, S. C. (2005). Climate information needs of Gascoyne-Murchison pastoralists: a representative study of the Western Australian grazing industry. Australian Journal of Experimental Agriculture 45, 1613-1625. doi: $10.1071 / \mathrm{EA} 04275$

McCown, R. L. (1981a). The climatic potential for beef cattle production in tropical Australia: Part I - Simulating the annual cycle of liveweight change. Agricultural Systems 6, 303-317. doi: 10.1016/0308-521X(81) 90065-2

McCown, R. L. (1981b). The climatic potential for beef cattle production in tropical Australia: Part III - Variation in the commencement, cessation and duration of the green season. Agricultural Systems 7, 163-178. doi: 10.1016/0308-521X(81)90044-5

McCown, R. L. (1982). The climatic potential for beef cattle production in tropical Australia: Part IV - Variation in seasonal and annual productivity. Agricultural Systems 8, 3-15. doi: 10.1016/0308-521X(82) 90088-9

McCown, R. L., Gillard, P., Winks, L., and Williams, W. T. (1981). The climatic potential for beef cattle production in tropical Australia: Part II Liveweight change in relation to agro-climatic variables. Agricultural Systems 7, 1-10. doi: 10.1016/0308-521X(81)90024-X

McDonald, C. K. (1994). Calculating climatic indices affecting plant growth. Tropical Agronomy Technical Memorandum No. 83, CSIRO Division of Tropical Crops and Pastures, Brisbane.

McKeon, G., and White, D. H. (1992). El Niño and better land management. Search 23, 197-200.

McKeon, G. M., Ash, A. J., Hall, W. B., and Stafford-Smith, D. M. (2000). Simulation of grazing strategies for beef production in north-east Queensland. In: 'Applications of Seasonal Climate Forecasting in Agricultural and Natural Ecosystems - the Australian Experience'. (Eds G. L. Hammer, N. Nicholls and C. Mitchell.) pp. 227-252. (Kluwer Academic Press: Dordrecht, The Netherlands.)

McKeon, G., Hall, W., Henry, B., Stone, G., and Watson, I. (2004). 'Pasture Degradation and Recovery in Australia's Rangelands.' (Department of Natural Resources, Mines and Energy: Brisbane.)

Nicholls, N. (2003). Climate change: are droughts becoming drier and more frequent? In: 'Science for Drought'. (Eds R. Stone and I. J. Partridge.) p. 173. (Queensland Department of Primary Industries: Brisbane.)

O'Rourke, P. K., Doogan, V. J., Entwistle, K. W., Fordyce, G., and Holroyd, R. G. (1991). Early seasonal indicators to aid management of cattle properties in north Australia. In: 'Agricultural Meteorology'. pp. 81-84. (National Committee on Agrometeorology: Melbourne.)

Park, J. N., Cobon, D., and Crabb, D. M. (2001). Integrating climate forecasts and geospatial systems to enhance grazing management in northern Australia. In: 'Geospatial Information and Agriculture Conference in Everleigh, NSW'. (NSW Agriculture: Sydney.)

Potts, J. M., Folland, C. K., Jolliffe, I. T., and Sexton, D. (1996). Revised 'LEPS' scores for assessing climate model simulations and long-range forecasts. Journal of Climate 9, 34-53. doi: 10.1175/1520-0442(1996) 009<0034:RSFACM $>2.0 . \mathrm{CO} ; 2$

Power, S., Tseitkin, F., Torok, S., Lavery, B., Dahni, R., and McAvaney, B. (1988). Australian temperature, Australian rainfall and the southern oscillation, 1910-1992: coherent variability and recent changes. Australian Meteorological Magazine 47, 85-101.

Reynolds, C. A., Yitayew, M., Slack, D. C., Hutchinson, C. F., Huete, A., and Petersen, M. S. (2000). Estimating crop yields and production by integrating the FAO crop specific water balance model with real-time satellite data and ground-based ancillary data. International Journal of Remote Sensing 21, 3487-3508. doi: 10.1080/014311600750037516 
Risbey, J., Karoly, D., Reynolds, A., and Braganza, K. (2003). Drought and climate change. In: 'Science for Drought'. (Eds R. Stone and I. J. Partridge.) pp. 8-11. (Queensland Department of Primary Industries: Brisbane.)

Rosenzweig, C., and Hillel, D. (1998). 'Climate Change and the Global Harvest.' (Oxford University Press Inc.: New York.)

Slatyer, R. O. (1964). General report on the lands of the Leichardt-Gilbert Area, Queensland, 1953-54. Part IV - Climate of the Leichardt-Gilbert Area. (CSIRO: Melbourne.)

Stone, R. C., and Auliciems, A. (1992). SOI phase relationships with rainfall in eastern Australia. International Journal of Climatology 12, 625-636. doi: 10.1002/joc.3370120608

Tothill, J. C., and Gillies, C. (1992). 'The Pasture Lands of Northern Australia: their Condition, Productivity and Sustainability.' (Tropical Grassland Society of Australia: Brisbane.)

Troup, A. J. (1965). The 'southern oscillation'. Quarterly Journal of the Royal Meteorological Society 91, 490-506. doi: 10.1002/qj. 49709139009
Tsonis, A. A., Elsner, J. B., Hunt, A. G., and Jagger, T. H. (2005). Unfolding the relation between global temperature and ENSO. Geophysical Research Letters 32, L09701. doi: 10.1029/2005GL022875

Walsh, K. J. E., Hennessy, K. J., Jones, R., McInnes, K., Page, C. M., Suppiah, R., and Whetton, P. (2001). 'Climate Change in Queensland under Enhanced Greenhouse Conditions: Third Annual Report, 1999-2000.' (CSIRO: Melbourne.)

Zhang, X. G., Fried, M. A., Schaaf, C. B., Strahler, A. H., Hodges, J. C. F., Gao, F., Reed, B. C., and Huete, A. (2003). Monitoring vegetation phenology using MODIS. Remote Sensing of Environment 84, 471-475. doi: 10.1016/S0034-4257(02)00135-9

Manuscript received 10 October 2008; accepted 29 December 2008 